\title{
Editorial
}

\section{Is Electronic Publishing Being Used in the Best Interests of Science? The Scientist's View*}

\section{R. Stephen Berry}

Department of Chemistry and the James Franck Institute, The University of Chicago, 5735 South Ellis Avenue, Chicago, Illinois 60637, USA. E-mail: berry@uchicago.edu, http://chemistrydev.uchicago.edu/fac/berry_group/

* Presented at the Second Conference on Electronic Publishing in Science held in Unesco House, Paris, France 19 - 23 February 2001 (http://associnst.ox.ac.uk/ icsuinfo/berryfin.htm)

Received: 2 May 2001 / Published: 28 June 2001

\begin{abstract}
The term "the best interests of science" must be interpreted from the viewpoints both of the scientists inside the enterprise and of the supporters and "users" affected by society's using the results of scientific research. This presentation will try to interpret the material presented throughout the Conference [1] in terms of both these viewpoints, but all within the context of this presenter's perspective, as a scientist, regarding "Why should we have science?" This presentation will be an overview and summary of many ideas that emerged in discussions in the Conference, with no attempt to attribute those ideas to individuals because so many of them were said by several participants, here and elsewhere. Furthermore, the perspective here is certainly that of the scientist, not of the publisher.
\end{abstract}

\section{Introduction}

Publishing through formal channels has long had a productive symbiosis with scientific research. Publishing in established, printed journals and monographs was the most efficient, reliable way for scientists to distribute and archive the results of their work. It was a reliable, profitable way for publishers to add essential value to the products of research, so it was also profitable for professional societies and commercial publishers.

Electronic publishing changed that situation. Distribution of their results by electronic means has already become an important alternative to distribution of printed paper, for working scientists. We are 
in a time of drastic transition, of exploration and unease, as established methods and institutions confront challenges from new, competitive alternatives. This meeting is itself part of our way of figuring out how to make our adaptation to the opportunities and perhaps threats of new technology.

The players in this world seem, perhaps, to have very distinct roles: the researchers, the supporters of the research, the publishers and the archivers. In fact, however, there are many overlaps among these roles that muddle how we can address the problem of adapting. Scientists belong to professional organizations, some of which survive financially by earning money from their publications. Librarians used to be the archivers and distributors of scientific information; with the advent of electronic means, that role can also be taken by journals themselves and by stand-alone archives such as that at Los Alamos that Paul Ginsparg created.

To understand how we might adapt to using electronic publishing, we must examine the motivations and responsibilities of these players. First, we need to recognize the motivations of the research scientists. This is something obvious to scientists but not to almost anyone outside that community. Scientists are not, for the most part, motivated to do research in order to make money. If they were, most would be in different fields. The primary motivation for most research scientists is the desire for influence and impact on the thinking of others about the natural world - unless the desire for their own personal understanding is even stronger. But in any case, earning an adequate income from doing science is taken to be an inevitable consequence of doing at least a competent job of research, a very indirect product of doing that research. The currency of the researcher is the extent to which her or his ideas influence the thinking of others. When one recognizes this, many aspects of scientific activity can be put into a coherent economic context and interpreted therefrom. But starting with a traditional business model, based on profit-making, one is sure to get an inappropriate picture of how the scientific world functions. What this implies is that distribution of the results of research has an extremely high priority for any working scientist, apart from those whose work is behind proprietary walls. Those are the situations in which the motivation for doing the research may be superseded by the motivations of those who support the research.

This brings us to the second group of players, the supporters of research. These fall into two categories, the private, for-profit firms and the governments and not-for-profit foundations. We shall consider the latter here primarily, because the former use traditional publication for only a selected part of their work, and a part considered off the main track that motivates their work. We must ask, "Why should or does a government or not-for-profit foundation support research?" The answer, in terms useful to us here, is easy to find: it is because the research so supported produces public goods in quantities large enough to justify the investment. We recall the economists' definition of a public good: a good whose value does not diminish with its use. The results of scientific research constitute a special (but not necessarily unique) kind of public good; the more those results are used, the greater is their value. This makes especially strong the importance of assuring that the results of publiclysupported research are distributed as widely as possible. Any activity that interferes with or hinders that distribution acts against the intent and implied interests of the government or other institution that supports the research. Any activity that enhances the distribution is acting to fulfill the goals of the research supporter.

The situation is not always altogether simple, of course. The research enterprise has many components and manifestations. Some government-supported research moves into the private, 
proprietary sector under provisions of the Bayh-Dole act. Some research is supported by a combination of private, industrial funds and government funds, as under the Advanced Technology Program and Small Business Industrial Research program. But here, since we are examining the way electronic publishing affects science, we focus on research that scientists would, traditionally, expect to appear in the professional literature. This means research that carries some risk of failure, and an unpredictable fraction of the successful work which will yield public goods - sooner or later.

Most scientists would probably say that professional organizations are important for the maintenance of a successful research establishment. Professional scientific societies have shown a wide range of ways of dealing with and adapting to electronic publication. Most scientists would also probably say that private publishing firms have largely played a positive role in sustaining the research enterprise. How the societies and the commercial publishers - and the research communities themselves - will distribute the results of research in the future is the challenge we face in this Conference. How can these continue to work to the mutual advantage of the publishers and the researchers, both as producers and consumers?

\section{What Next? How Do We Adapt?}

Many of the opportunities offered by electronic publication are apparent. Low-cost distribution to all parts of the world, search capabilities impossible with paper, linking, presentation of many kinds of information impossible in the fixed format of paper, all are now in use. We can probably expect people to discover and invent other new ways to use electronic publishing that we have not yet seen.

The controversies over how to adapt have focused heavily, thus far, on ownership of the intellectual property, on the rights and rules of its distribution, and on the role of certification or "refereeing". The issue of paying the costs arises as well, but, as we shall see, is properly classed as a secondary issue. The spectrum of opinion regarding ownership of scientific information has tended (but not exclusively) to follow the tradition of science publishing, in which the publisher takes ownership of copyright. This is in sharp contrast, for example, to how novels are handled; their authors typically retain the copyrights to their writing. Many people in the scientific world would now say that the most important question here, at least for the scientist, is not "Who owns the copyright?" but "Who has rights to distribute the results of research and what are those rights?" The American Physical Society has addressed this question by taking copyright but allowing the author virtually free rights to distribute the results of the research. Others, such as the American Chemical Society and the American Association for the Advancement of Science, have insisted on retaining both the copyright and the right to distribute the results in the form of publication, apart, of course, from the authors' rights to give away reprints they have purchases and to make fair-use copies of their publications.

The appearance of e-print archives such as xxx.lanl and PubMed Central has changed the situation because these are open, no-charge repositories. Each has its own rules for depositing material. The Los Alamos archive accepts papers without scientific review; PubMed Central requires refereeing. The Los Alamos archive accepts papers directly from their authors; PubMed Central takes papers from journals. Both, however, make themselves available without charge to anyone who can use the Internet. This is because they both are paid for by government funding. This is logically entirely plausible because, for the government that supports the research to achieve its goals, that government must see that the 
results of the research are indeed distributed as widely as possible. Furthermore the cost of distributing the results are never more than a tiny fraction of the total costs of the research; the added value from publishing the results is enormous.

Another change related to the e-print archives is the "virtual journal," that has no separate existence but is an access list of papers. The American Physical Society has begun some of these for specialized fields. Still closer to conventional journals are the all-electronic but refereed and edited journals such as the Internet Journal of Chemistry. These are examples of the new modes of publication that are still part of our experiments in adaptation.

PubMed Central is an intermediate between traditional print media translated into electronic form, as some commercial publishers now do, and open acceptance and distribution, as the Los Alamos archive does. PubMed Central distributes without charge, but its content is that of its member journals, such as Proceedings of the National Academy of Sciences of the U.S.A. This is a kind of compromise, that can assure that only reviewed works are in this archive. Of course each member journal has its own standards and procedures; there is no intent to maintain any uniform standard or threshold for admission of a paper.

The logical consequence of this reasoning, in a capitalist economy, is this: so long as there is an economically efficient private means of distributing the results of research, i.e. of "Publishing," then that can serve the communities that can use those results. If those modes of "Publishing" become inefficient, then "publishing," i.e. some other, non-traditional mode of distributing the results should come into play (to use the terminology of Martin Blume). This can take the form of distribution via an e-print archive, or of individual postings on a personal Web page, or of active transmission of manuscripts to a chosen audience. There will surely be other modes of "publishing" invented, too.

How do all these serve the ends of science? The most important characteristics that contribute positively are the wide distribution, the searchability, the linking and the negligible direct cost to the immediate user. These obviously bring a widening population into the scientific community, and enable research to be done in a more scholarly, responsible way. Unacknowledged rediscoveries will certainly happen, but their likelihood is reduced simply because the earlier literature can be searched. Even when they happen and are eventually recognized, it is likely that the merging of two or more independent recognitions of an idea will produce something more than the sum of the individual contributions. In other words, the increased transmission of existing information will make science advance faster and more effectively. Graduate students will learn of prior work that even their research directors did not know. The availability of links is a convenience that is fast becoming something we take for granted. It will become even more so as electronic publication grows.

What are the negatives for science, real or potential, associated with electronic publishing? One, in the belief of several professional societies, is that the professional societies will lose revenue and consequently lose effectiveness. Another is that commercial publishers will find scientific publication unprofitable and cease publishing their scientific journals and perhaps books. Still a third is that unrefereed articles may be irresponsible and outright wrong, and will mislead unwary readers. There of course have been substantive responses to each of these.

First, the professional societies are clearly institutions that the scientific communities want. Whether they are supported by dues, contributions, subscriptions or some other means is only a secondary question. The primary question, "Do the members of the societies and the scientific 
communities that use them want the professional societies enough to support them?" has an obvious answer - "Yes!" If subscriptions cease to be an effective way for societies to get their income, then they simply will have to use other means. If they want to continue to derive their income from publication, then they might move to modes such as publication charges. Or they could increase dues or fees for conferences. The communities simply won't let their professional organizations disappear. They might have to restructure, to "downsize" and trim budgets, but the commercial world has shown that this can be done without destroying the institutions.

Second, regarding commercial publishers, each of them has a responsibility to engage in those activities that they find are economically sound. There is no reason to assume that publishing The Journal of Extraterrestrial Biomedicine can remain profitable. If commercial publication of scientific journals is made obsolete by electronic publication, then so be it. If the community of scientists wants to continue the existence of The Journal of Extraterrestrial Biomedicine and its commercial publisher decides to drop that journal, then a professional society or an informal group of scientists must act on the motivation of the relevant community and produce an electronic journal, at very least, that will carry on publication. Moreover, to the extent that the research published in that journal is supported by government funding, the supporting governments have the responsibility to see that funds are available in some form to cover the costs of publication. Journals of this kind, with very small circulations, of order a few hundred subscribers, that serve relatively small communities of scientists who, by and large, know one another, are the ideal candidates for all-electronic, unrefereed, even unedited publication. The "papers" in such communities can be made available to everyone in the community for roughly $\$ 1$ per new publication, in terms of marginal cost, in contrast to $\$ 2-5,000$ for a fully reviewed and edited paper in a conventional journal.

We should not expect any single publishing model to be optimal for all the sciences. We should probably not even expect a single model to be the sole mode chosen by any single field with any sizeable number of researchers. Within a field as large as chemistry, we can expect many kinds of publishing to occur, ranging from the most open e-archives to the most protective, paper-oriented and traditional journal. This will be part of the process of adaptation that we are now experiencing. We should experiment, as much as possible, see how different modes work and evaluate the consequences of the various experiments. Let the different modes compete, and let's see which stay in use and can survive.

\section{Paying Costs}

Let us turn to paying the costs. The responsibility, as implied previously, for seeing that government-supported research results get published and distributed, falls ultimately to the government that supported the research. The publication costs are a tiny fraction of the costs of doing the research, so the marginal costs of publication are very small, but without publication, the results of the research cannot generate public goods, whose creation is the motivation for the support. (The question gets more complex if we examine public-private collaborations, but we avoid that issue today.) Not "Who should pay?" but "How should the payment be channeled?" is the appropriate way to address this issue. There are several possible modes, ranging from payment by author (via research grants) either as submission or page charges, through subscriptions to direct subsidies to journals. 
There are advantages and disadvantages to each; the glib answer is, "Choose the method that minimizes transaction costs." However there are secondary costs to some of these approaches that are difficult to evaluate, especially in the short term, so we can't expect to come to a simple answer, especially not to a single answer that will apply equally to all fields. We need to experiment with many modes, and to evaluate the consequences of each experiment.

This brings up a tricky point, particularly in the context of this UNESCO-ICSU meeting [1]. Many journals, especially those of highest quality and esteem, now publish articles from many countries. Journals are no longer national productions. How can we expect a German author to help support a journal published in the United States? The most obvious mechanism for this is for the journal to require payment of a publication charge. This, in turn, would mean that there would have to be an agreement among nations to pay such charges. At present, scientists in several nations are not permitted to pay such fees, according to the rules of their national science agencies. In principle, the total funds required for this would be the same or less than are now required, but now much of this money goes via overhead to support library subscriptions. This overhead should decrease if library subscription costs drop as commercial journals disappear, but we know that the libraries, pinched as they have been, are likely to substitute other purchases, rather than decrease their budgets, if some of their journals vanish. This means that a realistic way to face a transition from commercial paper journals to professional electronic journals may have to be some form of funding via research grants.

\section{Some Warnings}

One thing we want to avoid is any inhibitions on experiments with electronic publication. Each journal and archive should be free to make its own rules and set its own standards, but no journal or set of journals - or publisher or legislative body - should restrict any group or journal from carrying out its own experiment, so long as it violates no laws of plagiarism or theft. Restrictions at this time would be extremely counterproductive.

This brings us to a related issue for which some regulation is justified. As in all capitalistic situations, the market system works only if there is true competition and entry into the market is not prohibitive. At present, in the realm of scientific publication of "articles," there seems to be no particular threat of monopolization. However in the realm of publication of scientific databases, there is a very serious danger of monopolization and the loss of ready access by scientists to the data that makes their efforts possible. Some of this threat comes from the inappropriate application to scientific databases of reasoning regarding protection of privately-created databases intended for commercial use. Some of it comes from the threat of privatizing generation of scientific databases that were heretofore considered government responsibilities. Were there protection against monopoly in the database field, ways could perhaps be found to pursue some of the protective courses that have been proposed and even adopted, e.g. in the European Union's Database Directive. However without such protection, there is a very serious threat to the health of the scientific and technological enterprise. Database laws that virtually hand monopoly power to the first venturer into a database subject are likely to be severely damaging by destroying motivations for improvement or even for verification. Governments should stay in the business of distributing databases at the marginal cost of delivery whenever they have generated the data, and if they privatize the data generation, they must create a 
competitive market for the production and sale of the data. Otherwise, the governments have obligations to stay in the market as competitors of the private firms that would otherwise be monopolistic.

\section{Conclusions}

The most important theme we have identified is recognizing how important it is to keep open all the possibilities for experimentation and competition among various experiments. These should be experiments in openness to unlimited distribution, to forms of refereeing, to avenues for payment and pricing, and anything else we can try in adapting to electronic publication. As the results appear, we will have to take on the responsibility of evaluating and comparing the outcomes of these experiments. Each of us has her or his own guesses about which will succeed and which will evaporate, but the important thing now is to try.

\section{Note}

1. Presented at the Second Conference on Electronic Publishing in Science held in Unesco House, Paris, France 19 - 23 February 2001 (http://associnst.ox.ac.uk/ icsuinfo/berryfin.htm). The file of PowerPoint slides that accompanied the presentation of this paper are available on http://associnst.ox.ac.uk/ icsuinfo/berry.ppt.

(C) 2001 by MDPI (http://www.mdpi.org), Basel, Switzerland. 